\title{
O uso do Quincunx como recurso para o ensino de Probabilidade e Estatística*
}

\author{
$\underline{\text { Taís Aparecida Faria }}^{* *} \quad$ Natally Rodrigues Silva ${ }^{* *}$ \\ Instituto de Ciências Exatas, UNIFAL-MG \\ 37130-000, Alfenas, MG \\ E-mail: taisfariat@gmail.com, rodrigues_natally@hotmail.com \\ Denismar Alves Nogueira ${ }^{* * *}$ \\ Universidade Federal de Alfenas - Instituto de Ciências Exatas, UNIFAL-MG \\ 37130-000, Alfenas, MG \\ E-mail: denismar.nogueira@unifal-mg.edu.br
}

\begin{abstract}
RESUMO
No mundo atual é imprescindível ter conhecimentos básicos em Estatística e Probabilidade, pois é necessário analisar criticamente dados expostos em pesquisas, escolher amostras, entre outros. [2] evidencia a necessidade de obter respostas rápidas, e para isso se faz necessário conhecer a probabilidade da ocorrência de cada acontecimento e suas prováveis consequências para favorecer e agilizar a tomada de decisões e de fazer previsões. Assim sendo nota-se a importância do ensino de tal conteúdo na Educação Básica.

Tendo em vista que são os licenciados em Matemática os responsáveis pelo ensino de Probabilidade, [4] destaca que se espera que os professores conheçam os métodos utilizados em tais áreas, saibam a melhor forma de colher dados e também analisar criticamente as informações presentes em uma pesquisa, além disso, precisam conhecer a história, o intuito de se estudar a Estatística e a Probabilidade, e também como ensiná-la, como realizar a transposição didática.

Nesse sentido, os professores devem conhecer as tendências de ensino, tais como as destacadas por [1], formalista-clássica, a empírico-ativista, formalista-moderna, tecnicistamoderna, socioetnocultural, e a tendência construtivista. Esta última foi influenciada pelas ideias de Piaget, dá-se mais ênfase ao processo de ensino, onde o importante é aprender a desenvolver o raciocínio, os estudantes são incentivados a construir seu próprio conhecimento, com essa finalidade podem ser utilizados diversos recursos didáticos tais como o uso de materiais manipuláveis.

Segundo [3], materiais manipuláveis são objetos que os alunos podem tocar, sentir e movimentar, a fim de melhorar o processo de ensino aprendizagem, como exemplo temos alguns jogos, sendo o tangram e o material dourado exemplos muito conhecidos. Podem ser utilizados para motivar os estudantes, instigando-o a aprender o conteúdo, para auxiliar no processo de ensino-aprendizagem, ou para fixar o conteúdo.

Um recurso que pode ser utilizado pelos professores para o ensino de Probabilidade é o Quincunx, também conhecido como Tábua de Galton, este consiste em um objeto manipulável, no qual se observa a formação de curvas de densidade de probabilidades, assim sendo propõe-se mostrar tal recurso aos licenciandos em Matemática para que estes possam incorporá-lo a sua futura prática pedagógica.

O Quincunx consiste em um dispositivo com vários pinos dispostos em camadas intercaladas, um determinado número de esferas é lançado por um funil acima das camadas de
\end{abstract}

\footnotetext{
* O presente trabalho foi realizado com apoio financeiro da Fundação de Amparo a Pesquisa do Estado de Minas Gerais (FAPEMIG), Brasil.

*** Discente do Curso de Licenciatura em Matemática, Universidade Federal de Alfenas - MG.

**** Docente do núcleo de Estatística da Universidade Federal de Alfenas - MG.
} 
pinos, estas quando batem em cada um deles tem certa probabilidade de cair para o lado direito ou para o esquerdo.

Tomando a queda de uma determinada esfera como um evento, tem-se em cada pino onde esta bate, dois possíveis resultados, dessa forma pode-se notar o modelo de distribuição de Bernoulli. Depois de a esfera passar por $\mathrm{n}$ pregos a soma de eventos Bernoulli podem ser explicados pela distribuição Binomial, assim sendo, no final as canaletas que recebem as esferas desenham uma curva simétrica que pode ser representada pela densidade normal, isso quando a probabilidade de "cair para a direita" e "cair para a esquerda" é igual a 0,5 , já quando se tem outros valores, verifica-se curvas assimétricas.

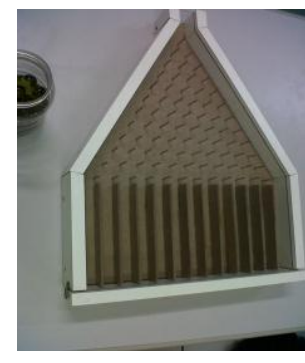

Figura 1: Quincunx

Neste estudo um Quincunx foi construído com materiais simples e de fácil acesso para ser utilizado em sala de aula com 15 discentes do segundo período curso de licenciatura em Matemática da Universidade Federal de Alfenas, como se pode observar na Figura 1. Além de utilizar o Quincunx também foi apresentada uma animação que está disponível no site Mathisfun ${ }^{1}$, pois se trata de um aparelho virtual onde se pode alterar parâmetros e consequentemente a curva de distribuição formada.

Tendo em vista que os discentes serão futuros professores na educação básica, foi também utilizado o software de geometria dinâmica Geogebra para mostrar algumas propriedades da distribuição normal, tais como o cálculo da área da função, a simetria existente, e também propriedades como assintótica em relação ao eixo $x$ e propriedades das assimétricas, de modo que os alunos conhecessem ainda outro modo de complementar o material disponível para as aulas de probabilidade, para se realizar a transposição didática de forma adaptada com o público-alvo da aula.

Após a aula foi aplicado um questionário, a fim de que os discentes opinassem sobre o uso do Quincunx como recurso no ensino de probabilidade e estatística. Foi relatado que o aparelho foi útil ao processo de ensino aprendizagem deles; fato que se nota ao observar um grande número de acertos nas questões que envolviam os conceitos de probabilidade desenvolvidos durante a aula. Respostas com mais erros foram verificadas quando se envolviam termos ainda não explorados teoricamente.

Assim sendo, evidencia-se o fato de que o Quincunx pode ser utilizado como recurso para a melhor compreensão de alguns conceitos de probabilidade tais como a média (esperança matemática), variância, distribuições de probabilidade e aproximações de uma distribuição discreta por uma contínua.

Palavras-chave: ensino de Matemática, materiais manipuláveis, distribuições de Probabilidade.

\section{Referências}

[1] D. Fiorentini, Alguns modos de ver e conceber o ensino da Matemática no Brasil, Zetetiké, Campinas, vol. 3, pp. 1-38, (1995).

[2] C. E. Lopes, O ensino da Estatística e Probabilidade na Educação Básica e na formação de professores, Centro de Estudos Educação e Sociedade, Campinas, vol. 28, pp. 57-73, (2008).

[3] A. M. Nacarato, Eu trabalho primeiro no concreto, Revista de Educação Matemática, vol. 23, pp. 1-6, (2005).

[4] A. S. Pamplona, D. L. de Carvalho, O ensino de Estatística na licenciatura em Matemática: a inserção do licenciando na comunidade de prática dos professores de Matemática, Bolema, Rio Claro, vol. 20, pp. 47-60, (2009).

\footnotetext{
${ }^{1}$ Disponível em: www.mathisfun.com/probability/quincunx.html.
} 